\title{
corRECTreatment: A web-based deci- sion support tool for rectal cancer treatment that uses the analytic hier- archy process and decision tree
}

\author{
A. Suner ${ }^{1, *} ;$ G. Karakülah" $2,3,{ }^{*} ; 0$. Dicle $^{3,4} ;$ S. Sökmen ${ }^{5} ;$ C.C. Çelikoğlu ${ }^{6}$ \\ ${ }^{1}$ Ege University, School of Medicine, Department of Biostatistics and Medical Informatics, Bornova-Izmir, 35040, Turkey; \\ ${ }^{2}$ Neurobiology-Neurodegeneration and Repair Laboratory, National Eye Institute, National Institutes of Health, Bethesda, Mary- \\ land, 20892, USA; \\ ${ }^{3}$ Dokuz Eylül University, Health Sciences Institute, Department of Medical Informatics, Inciraltı-Izmir, 35340, Turkey; \\ ${ }^{4}$ Dokuz Eylül University, School of Medicine, Department of Radiology, Inciraltı-Izmir, 35340, Turkey; \\ ${ }^{5}$ FACS, FASCRS, FASPSM Member from Dokuz Eylül University, School of Medicine, Department of General Surgery, Colorectal and \\ Pelvic Surgery Unit, Inciraltı-Izmir, 35340, Turkey; \\ ${ }^{6}$ Dokuz Eylül University, Faculty of Science, Department of Statistics, Buca-Izmir, 35160, Turkey; \\ *These authors contributed equally to this work.
}

\section{Keywords}

Clinical decision support, analytic hierarchy process, decision tree, rectal cancer

\section{Summary}

Background: The selection of appropriate rectal cancer treatment is a complex multi-criteria decision making process, in which clinical decision support systems might be used to assist and enrich physicians' decision making.

Objective: The objective of the study was to develop a web-based clinical decision support tool for physicians in the selection of potentially beneficial treatment options for patients with rectal cancer.

Methods: The updated decision model contained 8 and 10 criteria in the first and second steps respectively. The decision support model, developed in our previous study by combining the Analytic Hierarchy Process (AHP) method which determines the priority of criteria and decision tree that formed using these priorities, was updated and applied to 388 patients data collected retrospectively. Later, a web-based decision support tool named corRECTreatment was developed. The compatibility of the treatment recommendations by the expert opinion and the decision support tool was examined for its consistency. Two surgeons were requested to recommend a treatment and an overall survival value for the treatment among 20 different cases that we selected and turned into a scenario among the most common and rare treatment options in the patient data set.

Results: In the AHP analyses of the criteria, it was found that the matrices, generated for both decision steps, were consistent (consistency ratio $<0.1$ ). Depending on the decisions of experts, the consistency value for the most frequent cases was found to be $80 \%$ for the first decision step and $100 \%$ for the second decision step. Similarly, for rare cases consistency was $50 \%$ for the first decision step and $80 \%$ for the second decision step.

Conclusions: The decision model and corRECTreatment, developed by applying these on real patient data, are expected to provide potential users with decision support in rectal cancer treatment processes and facilitate them in making projections about treatment options. 


\section{Correspondence to:}

Aslı Suner

Ege University, School of Medicine, Department of Biostatistics and Medical Informatics

Bornova-Izmir, 35040, Turkey

Email: aslisuner@gmail.com

\section{Appl Clin Inform 2015; 6: 56-74}

http://dx.doi.org/10.4338/ACI-2014-10-RA-0087

received: October 6, 2014

accepted: December 22, 2014

published: February 4, 2015

Citation: Suner A, Karakülah G, Dicle O, Sökmen S, Çelikoğlu CC. corRECTreatment: A web-based decision support tool for rectal cancer treatment that uses the analytic hierarchy process and decision tree. Appl Clin Inf 2015; 6: 56-74 http://dx.doi.org/

10.4338/ACI-2014-10-RA-0087 


\section{Introduction}

Colorectal cancer treatment has recently gained a particular significance due to an increase in the observed number of new cases and deaths related to this disease causing it to rise to fourth place in cancer specific mortality [1-5]. Over 50.000 deaths are expected in the USA in 2014 due to colorectal cancer which is the second prevalent cancer type in women and the third one in men $[1,5]$.The five years survival rate of patients with colorectal cancer, which is generally observed in developed countries and thought to be due to Western dietary habits, is higher in women than men, while the incidence of cancer in women is lower when compared to men $[5,6]$.

Rectal and colon cancers are treated differently due to epidemiological and etiological differences [7]. This study deals with rectal cancer only. Involving different treatment options, patients with rectal cancer are sometimes treated with surgery, chemotherapy or radiotherapy; however, in some cases different combinations of these methods are used. We thought that a decision support tool for surgeons and oncologists would help them determine the correct methods for treatment.

The selection of the most appropriate method among different treatment options is closely related to the surgeon's experience and the patient's characteristics and preferences $[8,9]$. However, assessing numerous criteria related to tumor type, to patient and to surgeon is mostly challenging in the selection of the optimum rectal cancer treatment for a patient [7, 9-13]. In our previous study on the selection of an appropriate method in rectal cancer treatment, the treatment decision process, the criteria affecting this process and the levels of these criteria were defined and then the priorities of these criteria were determined using the Analytical Hierarchy Process (AHP) which is one of the decision making techniques used in operations research. In the AHP method, developed by Saaty in the 1970s, expert opinion is obtained via a questionnaire using pair wise comparison scale and considering the personal purposes of the decision makers, numerous criteria are compared by means of pair wise comparisons [14]. The reason for determining the priorities of the criteria used in the decision making process is the intention of assessing the process starting with the criterion with the highest priority when assessing numerous criterion in the decision support algorithm. In a complex decision process such as rectal cancer treatment, which depends on various criteria, the AHP method is an appropriate approach in providing decision support since it can straightly be adapted to the natural decision making processes of the decision maker [15]. In the present literature, it is possible to run across studies on priority determining use of the AHP for rectal cancer screening methods, but there is not any study, yet, on treatment methods using the AHP method [16-20].

Although there are many applications of decision trees in the medical domain, another method in providing decision support, very few of these studies are related to colorectal cancer. Present decision tree studies on colorectal cancer are mostly focused on cost-effectiveness analysis [21-26]. For example, Lee et al. developed a model using data mining methods for estimating the hospital cost of colorectal cancer patients [27]. In addition, Liu et al. devised a decision tree for modeling the colorectal cancer diagnosis using the serum proteins of the patients [28]. Minsky et al. also formed a consensus based decision tree making recommendations on rectal cancer treatment, and Vasen et al. devised a decision model which estimated and assessed the life expectancies of patients with familial adenomatous polyposis [29, 30].

In this study, we aimed to search the usability of a web-based decision support tool for rectal cancer treatment that utilizes the AHP and a decision tree made with the help of retrospectively collected patient data. The decision model for the selection of the most appropriate rectal cancer treatment method, which was developed in our previous study by combining the AHP method and decision tree approaches, was applied on patient data collected retrospectively [31]. For this purpose, the criteria, criteria levels and priorities were updated and a living web-based decision support tool named corRECTreatment built on patient data was formed. 


\section{Methods}

\subsection{Collection and Analysis of Patient Data}

The decision support model developed in our previous study was applied to real patient data in this study [31]. The model applied to 565 cases, which were treated for rectal cancer between 1988 and 2010 at Dokuz Eylül University, School of Medicine, General Surgery Department, and the data on the criteria pertaining to these decisions were extracted manually from patient records retrospectively. The records with missing data were excluded and 388 of the remaining patient records were used in the study. Patients in our data set were staged with the TNM system, with the help of imaging studies. CT, ERUS and high resolution pelvic MRIs were performed due to their availability. In recent years high resolution pelvic MRI, with phased array coils, was the only preoperative staging imaging option available in our institute.

It was found that not all of the criteria in the decision model, developed in the previous study were included in the data set comprising of the 388 patient records. Therefore, the priority determination using the AHP method was repeated for the decision model, which was updated with reference to the criteria in the patient data set, and the criteria priorities were recalculated. To check the consistency of the AHP analyses for both steps, the consistency ratios were computed. Saaty (14) suggests that the consistency ratio is acceptable when it does not exceed 0.10 . While the consistency ratio is equal or lower than 0.10 , the matrix is consistent and the expert's judgments are acceptable. Later, by means of the decision tree formed using these priorities, the recommended treatment methods, with regard to the determined criteria levels, and the probabilities of the treatment methods were designated. In the analysis of priority determination, the Expert Choice 2000 second edition software, developed especially for the AHP method applications, was used. The drawing of decision tree was performed with the Smart Draw 2008 software. Next, the treatment method or methods, to be recommended to each patient with the determined criteria levels, were listed from the highest probable one to the lowest one. In addition, the average overall survival values for the treatment method to be recommended by the decision support tool were calculated from the patient data. Lastly, frequency tables pertaining to all patient records were formed. IBM SPSS Version 20.0 software package was used to form frequency tables.

\subsection{Development of the Decision Support Tool}

A decision support tool we called CorRECTreatment was developed with PHP scripting language (version 5.3.10) and MySQL database (version 5.5.31) on Apache (version 2.2.4) Linux Server (http://php.net, http://www.mysql.com/). The user interfaces were created using HTML, and the basic operations of decision support tool were coded in PHP. Furthermore, the user interfaces of CorRECTreatment were made as easy to use as possible with the addition of Javacript and JQuery UI elements (http://jqueryui.com/). Patient records, treatment decisions, and criteria were stored in MySQL database. The communication between the user interfaces of CorRECTreatment and MySQL database was performed with PHP scripts.

In order to examine the consistency of the treatment recommendations obtained after applying the decision model, developed via the AHP method, on the patient data set, two different general surgeons were consulted, at Dokuz Eylül University, School of Medicine, General Surgery Department, who had not played a role in forming the decision model, and who had not participated in the decision steps in the data set. Both surgeons were requested to state the most appropriate treatment methods they would recommend in scenarios created for 20 different cases, common (10 cases) and rare (10 cases) in the patient data set. The possible first treatment and the additional treatment options were presented to the experts, and they were asked to confine their treatment and average overall survival values for the treatment recommendations within these treatment options (scenarios and the list of treatment options are available at http://webb.deu.edu.tr/tb/dsrct/sources.php). Later, treatment recommendations for the same cases were obtained from the decision support tool. Lastly, the compatibility of the treatment recommendations by the expert opinion and the decision support tool were examined for their consistency. 


\section{Results}

\subsection{Decision Model and Data Set}

There were 11 criteria in the first decision step of the decision model developed in our previous study and there were 14 criteria in the second step [31]. However, it was observed in the 388 patient records which were collected retrospectively, that the patient's performance level-ASA, the patient's attitude and the presence of rectal hematokesia criteria were not present in the first decision step and the location of the tumor, the coexisting disease and pathology, the efficacy level of treatment, the patient's performance level-Karnovsky, and the surgeon's experience criteria were not present in the second decision step. Therefore, the eight criteria that were not available in the patient data were not included in the newly formed decision model. The levels of the criteria coexisting disease or pathology in the first decision step and the pathologic prognostic factors in the second decision step were re-created as in $>$ Table 1 . Also, the level of the stage of the disease criterion in the second decision step was redefined as upstage, stable and downstage. The final version of the model, updated with regard to the patient data collected, can be seen in $>$ Table 1.

In the AHP analyses of the criteria, updated according to present patient data, it was found that the matrices, generated for both decision steps, were consistent (consistency ratio<0.1). While "the presence of perforation" criterion was found having the highest relative priority value, 0.331 , for the first decision step, the same criterion was the fifth with its 0.087 relative priority level in the second decision step ( $>$ Figure 1 ). The criterion with the lowest priority value, 0.024 , in the first decision step was the "coexisting disease or pathology". While "resection margin status" had the highest relative priority level, 0.214 , in the second decision step; "patient's age" was the one with the lowest relative priority level, 0.037 . After creating the decision tree using the criteria ordered according to the priorities determined via the AHP method, a model was obtained that could recommend appropriate treatment method based on the patient records data and according to the criteria levels. Since the decision tree drawn had a very complex branch structure, unfortunately, it could not be presented here.

The frequency tables pertaining to the criteria calculated based on patient data were examined, and shown at $>$ Table 2 and $>$ Table 3 . The frequencies pertaining to the preoperative and the adjuvant treatment recommendations and the types of surgical operation techniques for the model created from patient data were presented in $>$ Table 4 .

\subsection{Usage and Evaluation of the Decision Support Tool}

After developing the decision model here and its application to real patient data, a web-based decision support tool we called corRECTreatment, which could provide decision support to potential users based on real data, and the interfaces for this tool were prepared ( $>$ Figure 2). By means of the interface prepared here, access was provided to rectal cancer treatment recommendations, depending on the criteria selected, and the information about the average overall survival time for these recommendations.

Depending on the parameters selected by the user in the first step of the tool created here, the treatment methods, possible to administer to the patients, are listed in the first decision step. In addition, the user, optionally, could survey the possible treatment methods to be administered to the patient in the second decision step. After making appropriate selections for the 10 different criteria in the second decision step, the combinations of treatments at both the first and second steps, and their average survival time are presented in table format.

For instance, when a surgeon, who does at least 20 rectal interventions per year, wishes to determine the possible treatment options for a particular patient with no perforation, obstruction, invasion of adjacent organs and fistulas, with a T3N0M0 stage, the tumor being in the middle part of the rectum and who had no coexisting disease or pathology, five different methods were recommended by the tool. When the recommended methods were ordered from the most frequent to the least, "Low anterior resection + without preoperative chemoradiotherapy" with a 0.33 probability, "Preoperative chemoradiotherapy + low anterior resection" with 0.26, "Preoperative radiotherapy + low anterior resection" with 0.20 , "Preoperative chemoradiotherapy + very low anterior resection" 
with 0.13 , and "Preoperative chemoradiotherapy + abdominal perineal resection" with a 0.06 probability stand out.

In the next step, this patient, with a first treatment decision, was assumed to have additional examinations, his resection margin status to be R0, the stage of the disease to be stable, invasion of adjacent organs not to be present and the patient not to have any lymph, perineural or vascular invasion. In addition to these, in a situation where there is not any perforation and obstruction in the patient after the first step, the patient is younger than 80 , and the treatment is available in hospital conditions, the tool offers two separate treatment recommendations as additional treatments, "Adjuvant chemotherapy + adjuvant RT" and "Only adjuvant chemotherapy" with a probability of 0.50. As a result, the first and second step treatment decisions recommended by the tool is the "Low anterior resection + without preoperative chemoradiotherapy, then Adjuvant chemotherapy + adjuvant radiotherapy" with 178 months of survival, and "Low anterior resection + without preoperative chemoradiotherapy, then only adjuvant chemotherapy" with a 23 months survival. On the other hand, if a patient record matching the selected criteria is not present in the database, a warning is presented on the user screen and an average overall survival time is not presented.

When the treatment decisions and the average overall survival times recommended by the tool we developed here, and the expert opinions obtained from experts which did not participate in the study were assessed in order to test their consistencies, the consistency value for the most frequent cases was found to be $80 \%$ for the first decision step and $100 \%$ for the second decision step. Similarly, for rare cases, consistency was 50\% for the first decision step and $80 \%$ for the second decision step.

\section{Discussion and Conclusion}

In this study, an approach, devised in our previous study using AHP and decision tree methods, was applied to real patient data collected retrospectively. In addition, a web-based decision support tool, based on decision model and real patient data, was developed and formed the basis for an extendable and sustainable system that would facilitate the potential users' decision steps.

While obtaining the expert opinions via AHP method used for creating the decision model for patient-specific treatment options, equal contribution of the experts was ensured. On the other hand, there are approaches in which experts, performing the decision making, contributed to the study in different rates [15]. Even though there are different applications of AHP method in the medical domain, our study is original, since it both addresses rectal cancer treatment and applies the AHP combined decision tree method on real patient data $[16,17,20,32,33]$.

In our study, the classification and regression tree (C\&RT or CART) and C5.0 classification algorithms, consulted methods in data mining, were applied to the patient data. In recent years these techniques have been applied in a wide variety of life sciences related studies, including molecular genetics, risk assessment, early detection of heart failure and prediction of diabetes or prediabetes [34-38]. However, since the models developed here and their results of cross-validation are not favorable, the results of these methods were not included in the study. Besides, although multivariate statistical methods could also be used for devising a statistical model, it was found that these could not develop a model that would make treatment recommendations matching our data set.

The patient data, on which the decision model was applied, did not include all the criteria determined in our previous study. Therefore, the model based on the real patient data uses fewer criteria than the decision model developed in our previous study [31]. However, there is not any significant difference between the priorities obtained after the AHP analyses of both models, for which applications were conducted using real patient data. For instance, in both models, the one devised in our previous study and the one updated after obtaining patient data, the criterion with the highest priority was "the presence of perforation" for the first decision step; but it was not the same for the second decision step. In the first model, the highest priority criterion for the second step was "the surgeon's experience", while it was "resection margin status" for the updated model after removing "the surgeon's experience" criterion.

Because of the late-stage diagnosis of rectal cancer patients and the inherent aggressive biological behavior of distal rectal carcinomas, the combination of "preoperative chemoradiotherapy" and "ab- 
dominal perineal resection" treatment modalities were the most frequent treatment of the first decision step. For the same reasoning, "only adjuvant chemotherapy" was the most frequent therapeutic option for the second decision step in the locally advanced lymph node positive distal rectal tumors.

Lack of patient data corresponding to all cases under all branches of the decision tree of the model developed here or corresponding to treatment recommendations may be thought as a limitation of this study. The tool prepared here could not offer treatment recommendations if there is not any patient data corresponding to the criteria selected by the user, and shows a warning that patient data corresponding the selected criteria could not be found. However, with the extendable structure of the patient record data base, which would allow the addition of new patient data, it is possible to enrich the database with new patient data collected retrospectively and/or prospectively. Thus, some of the unusable branches of the decision tree could be used and it would be possible to obtain treatment options and average survival values pertaining to these branches. Besides, considering that the patient data was only collected from the General Surgery Department at Dokuz Eylul University, it is of great importance for the wide usability of the approach devised here, to add patient data collected by different institutions. Additionally, the tumor related factor, the pathological factors, and surgeon-related factor that is the resection margin status are not at hand at the initial treatment status. In retrospective analysis, we preferred to include these strong prognostic factors in the study. However, for the prospective usage of this tool, we will plan to use these two criteria at each time point a decision needs to be made. Our onging study, which aims to develop a prospective approach that will continuously learn and redesign its algorithm, with the additional patient data will provide a more dynamic decision support system.

While there are various cost-effectiveness analysis studies on lifetime cost estimation, cost-efficiency of diagnostic methods and screening methods in colorectal cancer the cost-efficiency of different treatment options for the same disease has not been studied before in detail. Therefore, a study on the cost-effectiveness of different treatment options with regard to the health institution, patient and physician is considered as a future study and it is planned to integrate this study into the decision support system developed here.

When the consistency of the recommendations offered, by the web-based tool developed here, for each decision step for various cases and the recommendations of the two experts, not participating in the study, for the same cases examined, it can be thought that the results for such a newly designed decision support system is promising. The consistency in the recommendations by the tool and the experts also indicates that the decision model, obtained after being updated with patient data, can be acknowledged as valid and useful in ensuring consistency. Also, if the tool, which could also be used in intern training, is integrated to the hospital information system it could be run in full with the prospectively collected patient data. It is possible to freely access the tool developed here from http://webb.deu.edu.tr/tb/dsrct/ .

In conclusion, the decision model and the web-based clinical decision support tool, developed by applying these criteria on real patient data, are expected to provide potential users with decision support in rectal cancer treatment processes and facilitate them in making projections about treatment options.

\section{Clinical Relevance}

In this research a web-based clinical decision support tool we called corRECTreatment was developed for physicians such as surgeons or oncologists to provide decision aid in the selection of potentially appropriate treatment methods in rectal cancer. The tool, based on a two-step decision model, allows its users to view (i) the beneficial treatment option(s) recommended in the first and second decision steps separately, (ii) the combination(s) of treatment options in both the first and second steps and (iii) their expected average overall survivals depending on the user defined parameters and available patient data.

\section{Conflict of Interest}

The authors declare that they have no conflict of interest in the research.

\section{Protection of Human and Animal Subjects}

In this research, 565 cases treated for rectal cancer between 1988 and 2010 at Dokuz Eylul University, School of Medicine, General Surgery Department, and the data on the criteria pertaining to 
these decisions were extracted from patient records retrospectively. Ethics approval for the study was obtained from Dokuz Eylul University, Ethics Committee for Non-invasive Clinical Research (project ethics number: 2013/07-22, see project web site http://webb.deu.edu.tr/tb/dsrct/indiv/ EthicsCommitteeApproval.pdf for the copy of the ethics approval). The study was performed in compliance with the World Medical Association Declaration of Helsinki on Ethical Principles for Medical Research Involving Human Subjects.

\section{Acknowledgements}

We are grateful to the editor and four anonymous referees for their valuable comments and suggestions on an earlier version of the manuscript. We would like to thank the general surgeons Tarkan ÜNEK and Tufan EGELI for giving their opinions in the evaluation of the results generated by the decision support tool. Özgün KOŞANER, Gail SEABOLD and Koray Doğan KAYA are acknowledged for their English editing. 
Priorities with respect to:

Combined

Priorities with respect to:
Goal: Decision making for surgery, other treatments or nothing for rectal cancer patients

Presence of perforation

Presence of obstruction

Presence of adjacent organ invasion

Presence of fistula

Surgeon's experience

Stage of the disease

Localization of the tumor

Coexisting disease or pathology

Inconsistency $=0,03$

with 0 missing judgments.

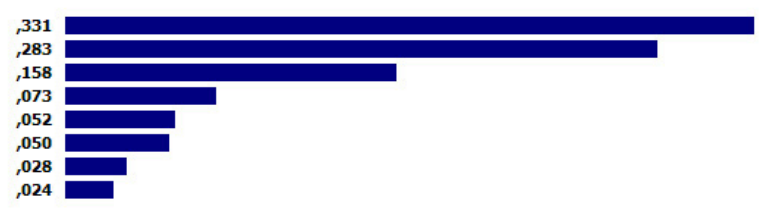

Priorities with respect to:

Goal: Decision making as regards the need for additional treatment Combined

Resection margin status

Stage of the disease

Presence of adjacent organ invasion

Pathologic prognostic factors

Presence of perforation

Presence of obstruction

Availability of treatment

Patient's age

with 0 missing judgments.
wistency $=0,01$

Fig. 1 The priority values of the model created from patient data via AHP method.

\section{corRECTreatment: a web-based decision support tool for rectal cancer treatment}

Home Start here Sources Contact

1. Decision making for the first treatment method

In this tep you will he askers the following questions regarding the patient with restal canser ard the surgern who will he performet the

operatlon. You can vlew the exp.anatlon of each questlon slmply moving your Touse over the questlon mark, Atter you select appropilate eption fo- each question clikk "'kext" button locas

a. Piesence ur peifurution? Yes No

b. Presence of obstruction? Yes Vo

c. Adjacent organ invasion? Yes No

d. Presence of fistula? yes No

e. Surgeon's experience? Lower than 20 yedrs Equal ul upper therl 20 yedrs

f. Disease Stage (TNM)? -3 NO MO

g. Iumor location? Lowcr Modlc Upocr

h. Conxissing discase? Absent Diabetes mel.itus Ilypertension Coronary artery d sease

(hronic nhstrutive pulmonary disease (hronic liver tailure other

Fig. 2 The screenshot of the first decision step of corRECTreatment. 
corRECTreatment: a web-based decision support tool for rectal cancer treatment

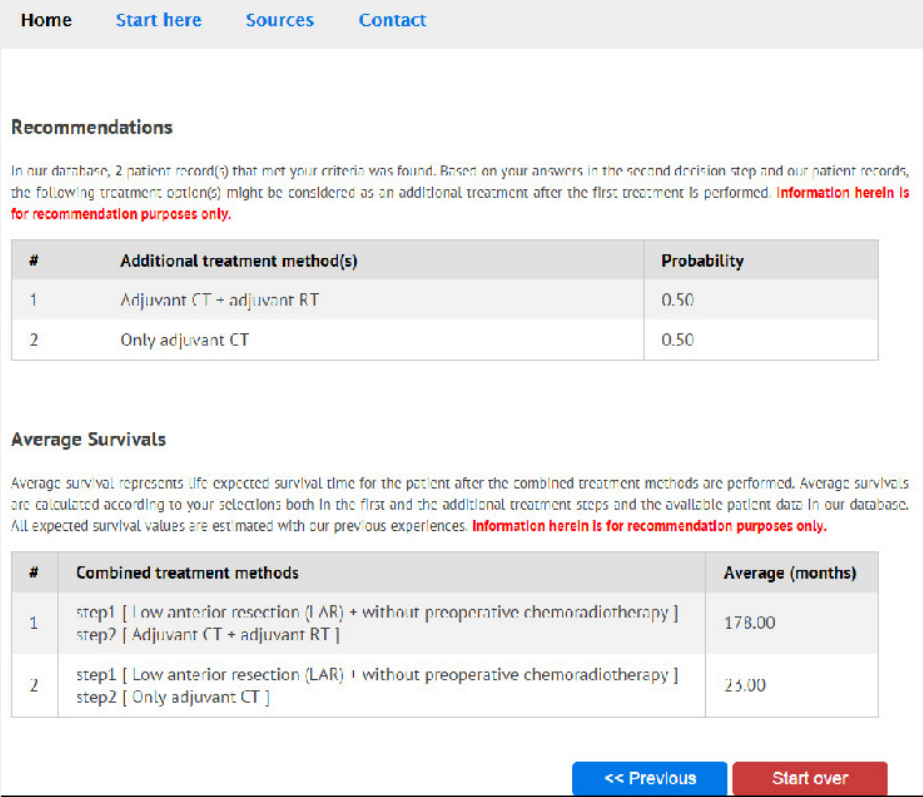

Fig. 3 The screenshot of the tool offering treatment recommendation and presenting expected survival times. 


\section{The First Decision Step}

\begin{tabular}{|c|c|}
\hline 1) Stage of the disease (TNM)* & $\begin{array}{l}\text { T1 N0 M0 } \\
\text { T2 N0 M0 } \\
\text { T3 N0 M0 } \\
\text { T4 N0 M0 } \\
\text { T1 N1 M0 } \\
\text { T2 N1 M0 } \\
\text { T3 N1 M0 } \\
\text { T4 N1 M0 } \\
\text { T1 N2 M0 } \\
\text { T2 N2 M0 } \\
\text { T3 N2 M0 } \\
\text { T4 N2 M0 } \\
\text { T1 N0 M1 } \\
\text { T2 N0 M1 } \\
\text { T3 N0 M1 } \\
\text { T4 N0 M1 } \\
\text { T1 N1 M1 } \\
\text { T2 N1 M1 } \\
\text { T3 N1 M1 } \\
\text { T4 N2 M1 } \\
\text { T1 N2 M1 } \\
\text { T2 N2 M1 } \\
\text { T3 N2 M1 } \\
\text { T4 N2 M1 }\end{array}$ \\
\hline 2) Location of the tumor & $\begin{array}{l}\text { Lower } \\
\text { Middle } \\
\text { Upper }\end{array}$ \\
\hline 3) Coexisting disease or pathology & $\begin{array}{l}\text { Present } \\
\text { - } \mathrm{DM}^{\mathrm{a}} \\
\text { - } \mathrm{DM}+\mathrm{HT}^{\mathrm{b}} \\
\text { - } \mathrm{DM}+\mathrm{CAD} \\
\text { - } \mathrm{DM}+\mathrm{CAD}+\mathrm{HT}+\text { Other } \\
\text { - } \mathrm{DM}+\mathrm{COPD^{d }} \\
\text { - } \mathrm{DM}+\mathrm{COPD}+\mathrm{HT} \\
\text { - } \mathrm{HT} \\
\text { - } \mathrm{HT}+\mathrm{O} \text { ther } \\
\text { - HT+CLF } \\
\text { - CAD } \\
\text { - CAD +HT } \\
\text { - CKF } \\
\text { - COPD } \\
\text { - COPD+HT } \\
\text { - COPD+CAD } \\
\text { - CLF } \\
\text { - Other } \\
\text { Absent }\end{array}$ \\
\hline 4) Invasion of adjacent organs & $\begin{array}{l}\text { Present } \\
\text { Absent }\end{array}$ \\
\hline 5) Surgeon's experience & $\begin{array}{l}\text { Lower than } 20 \\
\text { Equal or upper than } 20\end{array}$ \\
\hline 6) Presence of perforation & Absent \\
\hline 7) Presence of obstruction & Absent \\
\hline 8) Presence of fistula & Absent \\
\hline
\end{tabular}

Table 1 The criteria used in the decision steps of the model formed with patient data and their levels. 


\begin{tabular}{|l|l|}
\hline The Second Decision Step & \\
\hline 1) Stage of disease & $\begin{array}{l}\text { Upstage } \\
\text { Stable } \\
\text { Downstage }\end{array}$ \\
\hline 2) Invasion of adjacent organs & $\begin{array}{l}\text { Present } \\
\text { Absent }\end{array}$ \\
\hline 3) Lymph invasion & Present \\
& Absent \\
\hline 4) Perineural invasion & Positive \\
\hline 5) Vascular invasion & Negative \\
& Nonassessable \\
\hline 6) Patient's age & Present \\
\hline A) Resection margin status & Nonassessable \\
\hline & $0-80$ \\
\hline 8) Presence of perforation & Above 80 \\
\hline 9) Presence of obstruction & R0 \\
\hline 10) Availability of treatment & R1 \\
\hline R2 \\
\hline Absent
\end{tabular}

Table 1 Continued

*TNM is an international staging system for cancer. The grade of T expresses tumor size and extensions, $\mathrm{N}$ stands for the level of nodal invasion, $\mathrm{M}$ stands for the presence or absence of metastases.

aDM: Diabetes mellitus; ${ }^{b} \mathrm{HT}$ : Hypertension; 'CAD: Coronary artery disease; ${ }^{\mathrm{d} C O P D}$ : Chronic obstructive pulmonary disease; ${ }^{e}$ CLF: Chronic liver failure; ${ }^{f}$ CKF: Chronic kidney failure; 


\begin{tabular}{|c|c|c|}
\hline Criteria & Frequency & Percent \\
\hline \multicolumn{3}{|l|}{ Stage of disease } \\
\hline T1N0M0 & 11 & 2.8 \\
\hline T1N2M0 & 1 & 0.3 \\
\hline T2NOMO & 28 & 7.2 \\
\hline T2N0M1 & 2 & 0.5 \\
\hline T2N1M0 & 11 & 2.8 \\
\hline T2N2M0 & 3 & 0.8 \\
\hline T3NOMO & 58 & 14.9 \\
\hline T3N0M1 & 7 & 1.8 \\
\hline T3N1M0 & 68 & 17.5 \\
\hline T3N1M1 & 11 & 2.8 \\
\hline T3N2M0 & 52 & 13.4 \\
\hline T3N2M1 & 8 & 2.1 \\
\hline T3N3M1 & 1 & 0.3 \\
\hline T4NOMO & 28 & 7.2 \\
\hline T4N0M1 & 1 & 0.3 \\
\hline T4N1M0 & 39 & 10.1 \\
\hline T4N1M1 & 2 & 0.5 \\
\hline T4N2M0 & 42 & 10.8 \\
\hline T4N2M1 & 13 & 3.4 \\
\hline T4N3M0 & 1 & 0.3 \\
\hline T4N3M1 & 1 & 0.3 \\
\hline \multicolumn{3}{|c|}{ Location of the tumor } \\
\hline Lower & 153 & 39.4 \\
\hline Middle & 153 & 39.4 \\
\hline Upper & 82 & 21.1 \\
\hline \multicolumn{3}{|c|}{ Coexisting disease or pathology } \\
\hline Present & 121 & 31.2 \\
\hline - $\mathrm{DM}^{\mathrm{a}}$ & 17 & 4.4 \\
\hline - $\mathrm{DM}+\mathrm{HT}^{\mathrm{b}}$ & 13 & 3.4 \\
\hline - $\mathrm{DM}+\mathrm{CAD}$ & 4 & 1.0 \\
\hline - $\mathrm{DM}+\mathrm{CAD}+\mathrm{HT}+\mathrm{O}$ ther & 1 & 0.3 \\
\hline - $D M+C O P D^{d}$ & 1 & 0.3 \\
\hline - $\mathrm{DM}+\mathrm{COPD}+\mathrm{HT}$ & 1 & 0.3 \\
\hline$\bullet \mathrm{HT}$ & 44 & 11.3 \\
\hline - $\mathrm{HT}+$ Other & 2 & 0.5 \\
\hline - $\mathrm{HT}+\mathrm{CKF}^{\mathrm{e}}$ & 2 & 0.5 \\
\hline - CAD & 9 & 2.3 \\
\hline - $\mathrm{CAD}+\mathrm{HT}$ & 3 & 0.8 \\
\hline - CKF & 4 & 1.0 \\
\hline - COPD & 12 & 3.1 \\
\hline
\end{tabular}

Table 2 Frequency table for criteria in the first decision step of the model created from patient data and their levels. 


\begin{tabular}{|l|r|r|}
\hline Criteria & Frequency & Percent \\
\hline- COPD+HT & 2 & 0.5 \\
\hline - COPD+CAD & 1 & 0.3 \\
\hline - CLF & 1 & 0.3 \\
\hline - Other & 4 & 1.0 \\
\hline Absent & 267 & 68.8 \\
\hline Invasion of adjacent organs & \\
\hline Present & 46 & 11.9 \\
\hline Absent & 342 & 88.1 \\
\hline Surgeon's experience & & \\
\hline Lower than 20 & 43 & 11,1 \\
\hline Equal or upper than 20 & 345 & 88,9 \\
\hline Presence of perforation & & \\
\hline Present & 0 & 0 \\
\hline Absent & 388 & 100.0 \\
\hline Presence of obstruction & & 100.0 \\
\hline Present & 0 & 0 \\
\hline Absent & 388 & 100.0 \\
\hline Presence of fistula & & \\
\hline Present & 0 & 0 \\
\hline Absent & 388 & \\
\hline & & \\
\hline
\end{tabular}

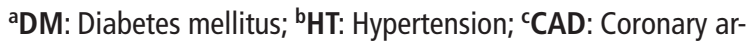
tery disease; ${ }^{\mathrm{d} C O P D}$ : Chronic obstructive pulmonary disease;

eCKF: Chronic kidney failure; ${ }^{\mathrm{f} C L F}$ : Chronic liver failure 


\begin{tabular}{|c|c|c|}
\hline Criteria & Frequency & Percent \\
\hline \multicolumn{3}{|c|}{ Stage of disease } \\
\hline Upstage & 36 & 9.3 \\
\hline Stable & 131 & 33.8 \\
\hline Downstage & 221 & 57.0 \\
\hline \multicolumn{3}{|c|}{ Invasion of adjacent organs } \\
\hline Present & 14 & 3.6 \\
\hline Absent & 374 & 96.4 \\
\hline \multicolumn{3}{|c|}{ Pathologic prognostic factors } \\
\hline \multicolumn{3}{|l|}{ Lymph invasion } \\
\hline Present & 106 & 27.3 \\
\hline Absent & 208 & 53.6 \\
\hline Nonassessable & 74 & 19.1 \\
\hline \multicolumn{3}{|c|}{ Perineural invasion } \\
\hline Present & 94 & 24.2 \\
\hline Absent & 218 & 56.2 \\
\hline Nonassessable & 76 & 19.6 \\
\hline \multicolumn{3}{|c|}{ Vascular invasion } \\
\hline Present & 67 & 17.3 \\
\hline Absent & 245 & 63.1 \\
\hline Nonassessable & 76 & 19.6 \\
\hline \multicolumn{3}{|l|}{ Patient's age } \\
\hline $0-80$ & 364 & 93.8 \\
\hline Above 80 & 24 & 6.2 \\
\hline \multicolumn{3}{|c|}{ Resection margin status } \\
\hline RO & 368 & 94.8 \\
\hline R1 & 18 & 4.6 \\
\hline R2 & 2 & 0.5 \\
\hline \multicolumn{3}{|c|}{ Presence of perforation } \\
\hline Present & 0 & 0 \\
\hline Absent & 388 & 100.0 \\
\hline \multicolumn{3}{|c|}{ Presence of obstruction } \\
\hline Present & 0 & 0 \\
\hline Absent & 388 & 100.0 \\
\hline \multicolumn{3}{|c|}{ Availability of treatment } \\
\hline Accessible & 388 & 100.0 \\
\hline Not accessible & 0 & 0 \\
\hline
\end{tabular}

Table 3 Frequency table for criteria in the second decision step of the model created from patient data and their levels. 


\begin{tabular}{|c|c|c|}
\hline Treatment Options & Frequency & Percent \\
\hline \multicolumn{3}{|l|}{ Preoperative $\mathrm{CRT}^{\mathrm{a}}$} \\
\hline Present & 231 & 59.5 \\
\hline Absent & 129 & 33.2 \\
\hline Preoperative $\mathrm{RT}^{\mathrm{b}}$ & 28 & 7.2 \\
\hline \multicolumn{3}{|l|}{ Operation Technique } \\
\hline$A P R^{c}$ & 113 & 29.1 \\
\hline$A R^{d}$ & 19 & 4.9 \\
\hline Hartmann operation & 10 & 2.6 \\
\hline $\operatorname{LAR}^{\mathrm{e}}$ & 146 & 37.6 \\
\hline Palliative treatment & 3 & 0.8 \\
\hline TEM $^{f}$ & 1 & 0.3 \\
\hline VLAR ${ }^{g}$ & 94 & 24.2 \\
\hline ISRx $x^{h}$ & 1 & 0.3 \\
\hline CAA $^{i}$ & 1 & 0.3 \\
\hline \multicolumn{3}{|l|}{ Adjuvant $\mathrm{CT}^{\mathrm{j}}$} \\
\hline Present & 287 & 74.0 \\
\hline Absent & 101 & 26.0 \\
\hline \multicolumn{3}{|l|}{ Adjuvant $\mathrm{RT}^{\mathrm{k}}$} \\
\hline Present & 52 & 13.4 \\
\hline Absent & 336 & 86.6 \\
\hline \multicolumn{3}{|c|}{ Treatment combination for the first decision step } \\
\hline Preoperative RT + APR & 12 & 3.1 \\
\hline Preoperative RT + AR & 8 & 2.1 \\
\hline Preoperative RT + Hartmann operation & 1 & 0.3 \\
\hline Preoperative RT + LAR & 6 & 1.5 \\
\hline Preoperative RT + VLAR & 1 & 0.3 \\
\hline Preoperative CRT + APR & 82 & 21.1 \\
\hline Preoperative CRT + Hartmann operation & 3 & 0.8 \\
\hline Preoperative CRT + ISRx & 1 & 0.3 \\
\hline Preoperative CRT + LAR & 68 & 17.5 \\
\hline Preoperative CRT + CAA & 1 & 0.3 \\
\hline Preoperative CRT + VLAR & 76 & 19.6 \\
\hline APR + without preoperative CRT & 19 & 4.9 \\
\hline AR + without preoperative CRT & 11 & 2.8 \\
\hline Hartmann operation+without preoperative CRT & 6 & 1.5 \\
\hline LAR + without preoperative CRT & 72 & 18.6 \\
\hline Palliative treatment+without preoperative CRT & 3 & 0.8 \\
\hline TEM + without preoperative CRT & 1 & 0.3 \\
\hline VLAR + without preoperative CRT & 17 & 4.4 \\
\hline
\end{tabular}

Table 4 Frequency table pertaining to treatment recommendations for the model created from patient data. 


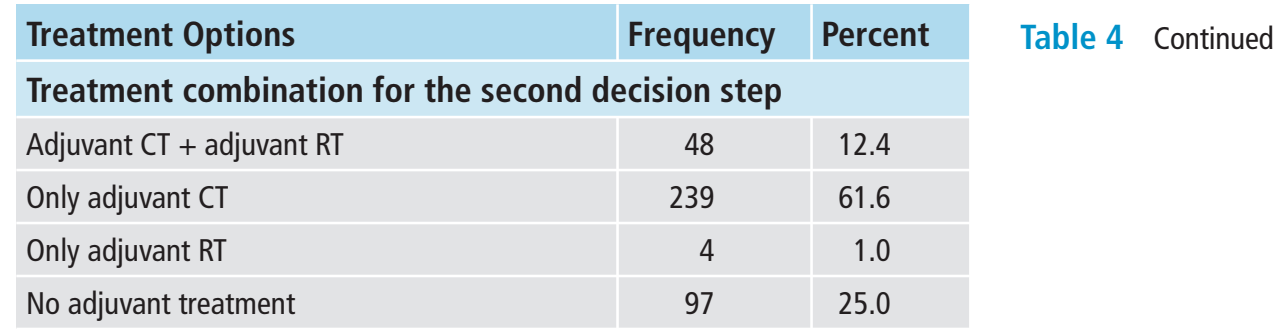

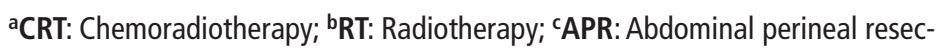
tion; ${ }^{\mathrm{A} A R}$ : Anterior resection; 'LAR: Low anterior resection; ${ }^{\mathrm{T} T E M}$ : Transanal endoscopic microsurgery; ${ }^{9 V L A R}$ : Very low anterior resection; ' teric resection; ' $\mathrm{CAA}$ : Colo-anal anastomosis; ${ }^{\mathrm{i} C T}$ : Chemotherapy; ${ }^{\mathrm{k}} \mathrm{RT}$ : Radiotherapy 


\section{References}

1. Siegel R, Ma J, Zou Z, Jemal A. Cancer statistics, 2014. CA Cancer J Clin 2014; 64: 9-29.

2. Hassan C, Hunink MG, Laghi A, Pickhardt PJ, Zullo A, Kim DH, Iafrate F, Di Giulio E. Value-of-information analysis to guide future research in colorectal cancer screening. Radiology 2009; 253: 745-752.

3. Walsh JME, Terdiman JP. Colorectal cancer screening: scientific review. JAMA 2003; 289: 1288-1296.

4. Howlader N, Noone A, Krapcho M, Neyman N, Aminou R, Waldron W, Altekruse SF, Kosary CL, Ruhl J, Tatalovich Z, Cho H, Mariotto A, Eisner MP, Lewis DR, Chen HS, Feuer EJ, Cronin KA, Edwards BK (eds). SEER Cancer Statistics Review, 1975-2008. National Cancer Institute Bethesda, MD. 2011.

5. Ferlay J, Shin HR, Bray F, Forman D, Mathers C, Parkin DM. Estimates of worldwide burden of cancer in 2008: GLOBOCAN 2008. Int J Cancer 2010; 127: 2893-2917.

6. Abreu MH, Matos E, Pocas FC, Rosa R, Jorge P. Rectal cancer epidemiology. Rectal Cancer - A Multidisciplinary Approach to Management. InTech; 2011. p. 3.

7. Popa F, Bratucu M, Radu P. Present and future tense in operable rectal cancer. Chirurgia (Bucur) 2010; 106(1): 11-16.

8. Wu JS, Fazio VW. Management of rectal cancer. J Gastrointest Surg 2004; 8(2): 139-149.

9. Porter GA, Soskolne CL, Yakimets WW, Newman SC. Surgeon-related factors and outcome in rectal cancer. Ann Surg 1998; 227(2): 157-167.

10. Bosset J-F, Collette L, Calais G, Mineur L, Maingon P, Radosevic-Jelic L, Daban A, Bardet E, Beny A, Ollier JC; EORTC Radiotherapy Group Trial 22921. Chemotherapy with preoperative radiotherapy in rectal cancer. N Engl J Med 2006; 355(11): 1114-1123.

11. Taflampas P, Christodoulakis M, de Bree E, Melissas J, Tsiftsis DDA. Preoperative decision making for rectal cancer. Am J Surg 2010; 200(3): 426-432.

12.Stocchi L, Nelson H, Sargent DJ, O’Connell MJ, Tepper JE, Krook JE, Beart R Jr; North Central Cancer Treatment Group. Impact of surgical and pathologic variables in rectal cancer: a United States community and cooperative group report. J Clin Oncol 2001; 19(18): 3895-3902.

13. Chang GJ, Kaiser AM, Mills S, Rafferty JF, Buie WD. Practice parameters for the management of colon cancer. Dis Colon Rectum 2012; 55(8): 831-843.

14. Saaty TL. How to make a decision: The analytic hierarchy process. Eur J Oper Res 1990; 48(1): 9-26.

15. Pecchia L, Bath PA, Pendleton N, Bracale M. Analytic Hierarchy Process (AHP) for examining healthcare professionals' assessments of risk factors. The relative importance of risk factors for falls in communitydwelling older people. Methods Inf Med 2011; 50(5): 435-444.

16.Dolan JG, Frisina S. Randomized controlled trial of a patient decision aid for colorectal cancer screening. Med Decis Making 2002; 22(2): 125-139.

17. Dolan JG. Patient priorities in colorectal cancer screening decisions. Health Expect 2005; 8(4): 334-344.

18. Dolan JG. Shared decision-making-transferring research into practice: the Analytic Hierarchy Process (AHP). Patient Educ Couns 2008; 73(3): 418-425.

19.Dolan JG, Boohaker E, Allison J, Imperiale TF. Can Streamlined Multicriteria Decision Analysis Be Used to Implement Shared Decision Making for Colorectal Cancer Screening? Med Decis Making 2013; 34(6): 746-755.

20. Katsumura Y, Yasunaga H, Imamura T, Ohe K, Oyama H. Relationship between risk information on total colonoscopy and patient preferences for colorectal cancer screening options: analysis using the analytic hierarchy process. BMC Health Serv Res 2008; 8: 106.

21.Tilson L, Sharp L, Usher C, Walsh C, Whyte S, O’Ceilleachair A, Stuart C, Mehigan B, John Kennedy M, Tappenden P, Chilcott J, Staines A, Comber H, Barry M. Cost of care for colorectal cancer in Ireland: a health care payer perspective. Eur J Health Econ 2012; 13(4): 511-524.

22. Karuna ST, Thirlby R, Biehl T, Veenstra D. Cost-effectiveness of laparoscopy versus laparotomy for initial surgical evaluation and treatment of potentially resectable hepatic colorectal metastases: a decision analysis. J Surg Oncol 2008; 97(5): 396-403.

23. Annemans L, Lencioni R, Warie H, Bartolozzi C, Ciceri M, Müller U. Health economic evaluation of ferucarbotran-enhanced MRI in the diagnosis of liver metastases in colorectal cancer patients. Int J Colorectal Dis 2008; 23(1): 77-83.

24. Abbott DE, Cantor SB, Hu C-Y, Aloia TA, You YN, Nguyen S, Chang GJ. Optimizing clinical and economic outcomes of surgical therapy for patients with colorectal cancer and synchronous liver metastases. J Am Coll Surg 2012; 215(2): 262-270.

25. Pichereau S, Le Louarn A, Lecomte T, Blasco H, Le Guellec C, Bourgoin H. Cost-effectiveness of $\mathrm{UGT}_{1 \mathrm{~A}} 1^{\star} 28$ genotyping in preventing severe neutropenia following FOLFIRI therapy in colorectal cancer. J Pharm Pharm Sci 2010; 13(4): 615-625. 
26.Delcò F, Sonnenberg A. Limitations of the faecal occult blood test in screening for colorectal cancer. Ital J Gastroenterol Hepatol 1999; 31(2): 119-126.

27.Liu C, Pan C, Shen J, Wang H, Yong L. MALDI-TOF MS combined with magnetic beads for detecting serum protein biomarkers and establishment of boosting decision tree model for diagnosis of colorectal cancer. Int J Med Sci 2011; 8(1): 39-47.

28. Lee S-M, Kang J-O, Suh Y-M. Comparison of hospital charge prediction models for colorectal cancer patients: neural network vs. decision tree models. J Korean Med Sci 2004; 19(5): 677-681.

29. Minsky BD, Coia L, Haller D, Hoffman J, John M, Landry J, Pisansky TM, Willett C, Mahon I, Owen J, Hanks G. Treatment systems guidelines for primary rectal cancer from the 1996 Patterns of Care Study. Int J Radiat Oncol Biol Phys 1998; 41(1): 21-27.

30. Vasen HF, van Duijvendijk P, Buskens E, Bülow C, Björk J, Järvinen HJ, Bülow S. Decision analysis in the surgical treatment of patients with familial adenomatous polyposis: a Dutch-Scandinavian collaborative study including 659 patients. Gut 2001; 49(2): 231-235.

31. Suner A, Çelikoğlu CC, Dicle O, Sökmen S. Sequential decision tree using the analytic hierarchy process for decision support in rectal cancer. Artif Intell Med 2012; 56(1): 59-68.

32. Liberatore M, Nydick R. The analytic hierarchy process in medical and health care decision making: A literature review. Eur J Oper Res 2008; 189: 194-207.

33. Dolan JG. Involving patients in decisions regarding preventive health interventions using the analytic hierarchy process. Health Expect 2000; 3(1): 37-45.

34. Hsieh A-R, Hsiao C-L, Chang S-W, Wang H-M, Fann CSJ. On the use of multifactor dimensionality reduction (MDR) and classification and regression tree (CART) to identify haplotype-haplotype interactions in genetic studies. Genomics 2011; 97(2): 77-85.

35. Srivastava A, Sharma KL, Srivastava N, Misra S, Mittal B. Significant role of estrogen and progesterone receptor sequence variants in gallbladder cancer predisposition: a multi-analytical strategy. PLoS One 2012; 7(7): e40162.

36. Pecchia L, Melillo P, Bracale M. Remote health monitoring of heart failure with data mining via CART method on HRV features. IEEE Trans Biomed Eng 2011; 58(3): 800-804.

37. Melillo P, De Luca N, Bracale M, Pecchia L. Classification tree for risk assessment in patients suffering from congestive heart failure via long-term heart rate variability. IEEE J Biomed Heal informatics 2013; 17(3): 727-733.

38. Meng X-H, Huang Y-X, Rao D-P, Zhang Q, Liu Q. Comparison of three data mining models for predicting diabetes or prediabetes by risk factors. Kaohsiung J Med Sci 2013; 29(2): 93-99. 